\title{
Research on Foreign Assets Common Benefit Mechanism of Tobacco Farmer Cooperatives Based on Structural Equation Model
}

\author{
Jun Liu ${ }^{1, a^{*}}$, Feng Wang ${ }^{2, b}$, Bing Zhou ${ }^{2, c}$ \\ ${ }^{1}$ Guizhou University of Finance and Economics, Guiyang 550025 \\ ${ }^{2}$ Branch of Tobacco Company in Southwest Guizhou Province, Xingyi 562400 \\ aemail: liujunsucceed@163.com, ${ }^{\text {bemail: 479095320@qq.com, }{ }^{c} e m a i l: 5267865 @ q q . c o m ~}$
}

\begin{abstract}
Keywords: Tobacco farmer cooperatives; Structural equation model; Common benefit mechanism; Foreign asset

Abstract: First of all, the paper starts with present situation of foreign assets common benefit mechanism of tobacco farmer cooperatives, proposes a theoretical framework using structural equation model. The empirical analysis on effective sample of 262 farmers cooperatives finds institutionalization of financial management, standardization of financial management, relationship between tobacco enterprises and cooperatives, relationship between tobacco enterprises and farmers have a significant effect on farmers cooperatives common benefit mechanism.
\end{abstract}

\section{Introduction}

Tobacco companies carried out a large number of financial support and asset donation to tobacco farmer cooperatives. But some of the tobacco farmer cooperatives did not implement quantitative distribution about foreign subsidy assets and their income. Its beneficiaries are often just a handful of core members, which reduce the cohesion of cooperative to members, increase the loss risk of subsidy assets. Tobacco industry is a typical order agriculture. Tobacco companies implement order cultivation and subsidy system to farmers. In order to realize common benefit mechanism and fairness of subsidized inputs, tobacco companies guide farmers to set up cooperatives in the tobacco-growing areas, subsidy agricultural machinery, greenhouses, vehicles and other assets to cooperatives. Then cooperatives reuse these assets provide low-cost services to tobacco farmer members.

But in reality, some farmers cooperatives did not implement quantitative distribution of external subsidy assets. Its beneficiaries are often just a handful of core members. The amount of money in the member account column "quantify share of external subsidy funds" "quantify share of donated property" is random, so that the cohesion of cooperative to general members decline. How to improve asset utilization efficiency and reduce the asset losses, ensure subsidies assets can benefit each member, but not a few people. Under present situation that complexity of assets, absence of regulation, arbitrary of exit, opacity of earnings distribution, how to overcome democratic defects of cooperative governance and moral hazard of core members, achieve common benefit and fairness of foreign assets, which has become an important issue related to vitality and cohesion of cooperatives.

The domestic and foreign research on common benefit mechanism of tobacco farmer cooperatives is few. Zheng Weixin (2014), taking Liuyang city as an example, studied the development of farmer specialized cooperative and government support strategy. Results show that, through government support, cooperatives have two main ways to acquire foreign assets: direct project funding support and reward support funds. But policy guidance function of government support is not outstanding, financial support strength is limited, the applyment of funds that support the development of farmer specialized cooperatives is not reasonable and so on. In addition, the proportion of cooperatives that access to foreign assets donated by other social organizations or individuals accounted for study samples is $22.73 \%$, and the amount of donations is low ${ }^{[1]}$. Some researchers have studied farmer cooperatives operating mechanism in Shandong Province. Cooperatives get foreign assets through government financial support, the authors suggest that government should give targeted financial support, develop a number of more specification and 
demonstration cooperatives to promote farmers cooperatives development. When development has reached to a certain extent, state financial subsidies and other support policies can no longer have "Matthew Effect" phenomenon, but should focus on "common development and common prosperity", all farmers benefit is the ultimate goal ${ }^{[2]}$. Zhang Xiaoshan (2015) proposed, with right confirmation, registration and certification work, collective assets clear property rights, cure equity, land rights and real right. Its essence is to determine the eligible members respective share for collective assets or resources at a certain point, determine the fairness of starting point. Although the future development direction of collective economy should be from closed to open, from curing to flow, but curing is to get a better flow. On the basis of clear property rights, joint-stock cooperation is conducive to promoting the flow of equity, land rights and real right, increasing funding, expanding stocks ${ }^{[3]}$. But to orders enterprises investment subsidies or donations to the cooperatives foreign assets, we pay relatively little attention, attention to the property particularity of cooperatives foreign assets is also not enough.

\section{Theoretical Framework}

Farmer specialized cooperative as an independent economic organization, only establishing a sound cooperative financial management system, can we guarantee financial management of farmer specialized cooperative, and can promote the healthy and orderly cooperative development. Three measures to improve financial management system of farmer specialized cooperatives and strengthen accounting. First, relevant government departments should formulate different financial management system according to different types of farmer specialized cooperatives, standardize their accounting process; second, according to the principle of mutual separation, establish independent accounting jobs, avoid the phenomenon that the same person in the accounting and cashier, ensure strict cash management; third, strengthen examination and approval system. For "Farmer Cooperatives Financial Accounting System (Trial)", "Enterprise Accounting Standards", " Accounting Methods of Agricultural Enterprises" a comparative analysis to the similarities and differences between the three in agricultural assets accounting treatment, points out that the three have a great difference in livestock accounting and forest assets accounting. The columns in balance sheet are also clearly different. Aiming at these differences, author puts forward some suggestions for improvement, reducing the difference between the three to promote healthy development of farmer specialized cooperative.

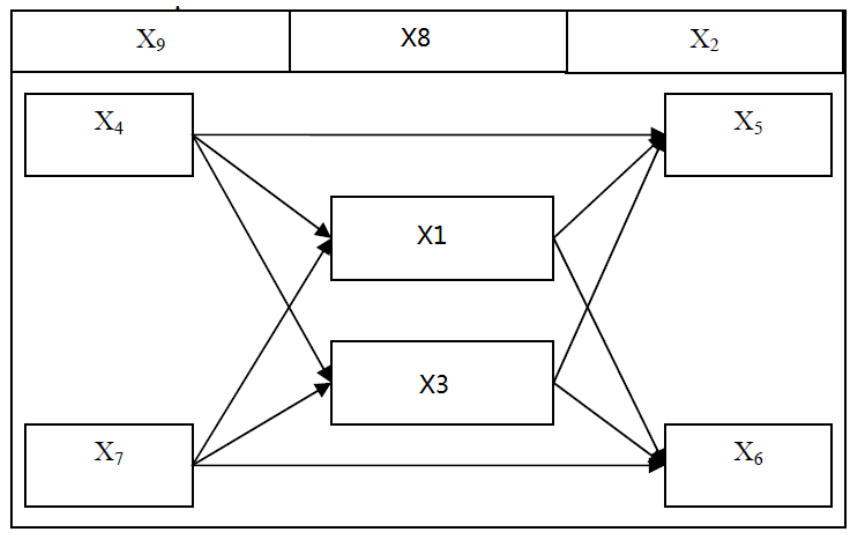

Fig. 1 Theoretical Framework of Research

Variable are explained as follows: Foreign assets $\left(\mathrm{X}_{1}\right)$, Common benefit mechanism $\left(\mathrm{X}_{2}\right)$, Tobacco farmers cooperatives $\left(\mathrm{X}_{3}\right)$, Financial management institutionalization $\left(\mathrm{X}_{4}\right)$, Enhance foreign assets utilization $\left(\mathrm{X}_{5}\right)$, Financial management standardization $\left(\mathrm{X}_{6}\right)$, Enhance intact rate of foreign $\operatorname{assets}\left(\mathrm{X}_{7}\right)$, Relationship between tobacco companies and cooperatives $\left(\mathrm{X}_{8}\right)$, Relationship between tobacco companies and tobacco growers $\left(\mathrm{X}_{9}\right)$. 


\section{Empirical Test}

\subsection{Questionnaire Design}

By referring to the previous research, we have carried out operational definition of involved structure. In the questionnaire, we use Likert seven point method to measure all the items. According to the questionnaire, numerical "1-7" is chosen to evaluate agreement degree between the subject and the object, 1 is completely consistent, 7 is totally not in agreement.

Financial management institutionalization: based on the research ${ }^{[4]}$ of E. H. Jette (2012), with four questions to measure items, which are the sound degree of financial management system, financial control ability, property control ability and ability to obtain capital.

Financial management standardization: this paper uses 2 questions to measure, that is, Fixed asset investment standardization, fixed asset depreciation standardization.

Relationship between tobacco companies and cooperatives: 4 questions are used to measure, which is property rights market, cooperative system, cooperatives governing ability, cooperative culture.

Relationship between tobacco companies and tobacco growers: 2 items were used to measure, namely, stability degree of tobacco farmers, closeness of tobacco farmers.

Tobacco farmers cooperatives: this paper draws on the research of J. Horbach (2007), using 2 questions to measure, one is to enhance foreign assets utilization, and the other is enhance intact rate of foreign assets.

\subsection{Data Collection}

In order to empirical test foreign assets common benefit mechanism of tobacco farmer cooperatives, this paper collects relevant statistical data through questionnaire survey. Taking into account the universality of this mechanism, research group gets a random sample of 300 farmers cooperatives from "Chinese farmers cooperatives list In 2014 year" announced by the Ministry of Agriculture, the eastern, central and west, respectively have 100. Through telephone survey, mail and electronic questionnaires, after two rounds of questionnaire surveys, we obtained valid samples of 262 growers cooperative, effective rate was 87.33 percent.

\subsection{Reliability and Validity Analysis}

Reliability and validity of questionnaire is analyzed by SPSS20.0 and AMOS19.0 software, test results are shown in Table 1 . Cranach's $\alpha$ of variables is $0.802-0.905$. Each variable has a high degree of reliability. The Mean variation extraction of each variable (AVE) is more than 0.6, composite reliability $(\mathrm{CR})$ is more than 0.9 . It shows that each constructs has high reliability and validity.

Table 1 Reliability and Validity Test

\begin{tabular}{|c|c|c|c|c|c|c|c|c|c|}
\hline Construct & Cronbach's $\alpha$ & $\begin{array}{l}\text { Factor } \\
\text { loading }\end{array}$ & AVE & $\mathrm{CR}$ & Construct & Cronbach's $\alpha$ & $\begin{array}{l}\text { Factor } \\
\text { loading }\end{array}$ & AVE & $\mathrm{CR}$ \\
\hline $\begin{array}{l}\text { Financial } \\
\text { Management } \\
\text { Institutionaliza } \\
\text { tion A } \\
\end{array}$ & 0.909 & & 0.663 & 0.912 & $\begin{array}{l}\text { Relationship } \\
\text { between tobacco } \\
\text { companies and } \\
\text { cooperatives C }\end{array}$ & 0.849 & & 0.594 & 0.852 \\
\hline SM1 & & 0.689 & & & CM1 & & 0.658 & & \\
\hline SM2 & & 0.607 & & & $\mathrm{CM} 2$ & & 0.716 & & \\
\hline SM3 & & 0.611 & & & $\mathrm{CM} 3$ & & 0.813 & & \\
\hline SM4 & & 0.752 & & & CM4 & & 0.876 & & \\
\hline $\begin{array}{l}\text { Financial } \\
\text { Management } \\
\text { Standardizatio } \\
\text { n B } \\
\end{array}$ & 0.924 & & 0.701 & 0.924 & $\begin{array}{l}\text { Relationship } \\
\text { between tobacco } \\
\text { companies and } \\
\text { tobacco growers D }\end{array}$ & 0.753 & & 0.521 & 0.762 \\
\hline DM1 & & 0.688 & & & $\mathrm{CC} 1$ & & 0.795 & & \\
\hline DM2 & & 0.748 & & & $\mathrm{CC} 2$ & & 0.848 & & \\
\hline $\begin{array}{l}\text { Farmers } \\
\text { Cooperatives E }\end{array}$ & 0.914 & & 0.607 & 0.918 & & & & & \\
\hline HB1 & & 0.858 & & & & & & & \\
\hline HD4 & & 0.814 & & & & & & & \\
\hline
\end{tabular}




\subsection{Establishment and Hypothesis Testing of Structural Equation Model}

\subsubsection{Build Structural Equation Modeling}

Using AMOS18.0 construct structural equation model to verify the hypothesis, fitting results are shown in Fig. 2.

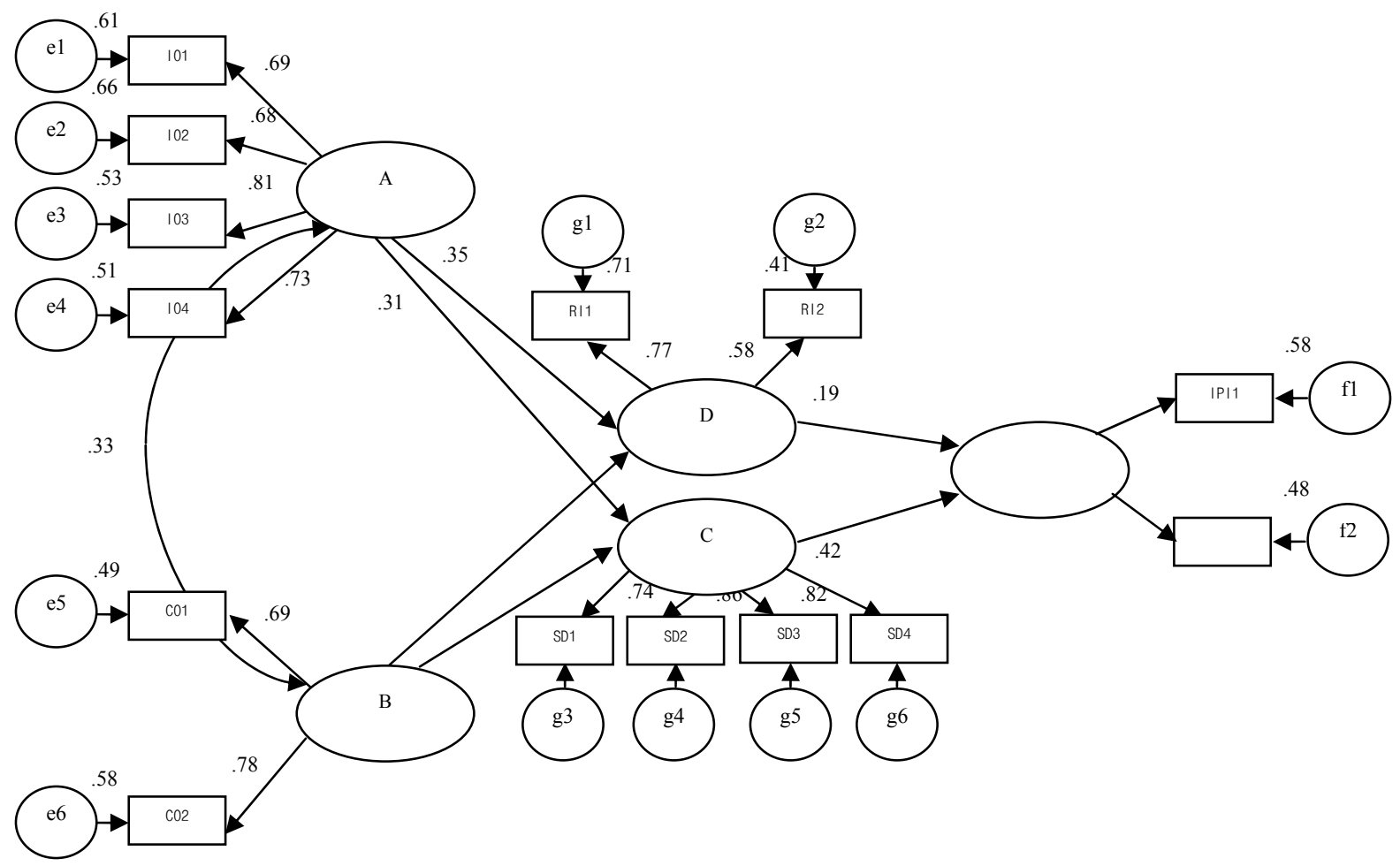

Fig. 2 Empirical Analysis of Structural Equation Modeling Data Graph

\subsubsection{Model Fitting Inspection}

As shown in Table 2, indicators fitting have reached the accuracy requirements, which shows that the fitting effect is good and the whole fitting degree of structural equation model can meet the requirements. Therefore, the scale has the whole construct validity.

Table 2 Overall Fitting Degree Statistics

\begin{tabular}{llllllll}
\hline Fitting index & CMIN/DF & GFI & AGFI & IFI & CFI & RMSEA & NNFI \\
\hline Fitting results & 2.857 & 0.943 & 0.929 & 0.831 & 0.805 & 0.072 & 0.885 \\
\hline Fitting accuracy standard & $2-3$ & $>0.9$ & $>0.9$ & $>0.8$ & $>0.8$ & $<0.09$ & $>0.8$
\end{tabular}

In summary, the empirical analysis on 262 valid samples of farmers cooperatives found that financial management institutionalized, financial management standardization, relationship between tobacco companies and cooperatives, relationship between tobacco companies and tobacco growers have a significant effect on common benefit mechanism of tobacco farmer cooperatives.

\section{Conclusion and Enlightenment}

With the rapid development of order agriculture and farmer organization, increasing strength of leading enterprises back-feeding agriculture, research on foreign assets common benefit mechanism of tobacco farmer cooperatives is imminent. The cooperative has the characteristics of complexity of assets, absence of supervision, randomness of exit and opacity of earnings distribution. In the future, we should from the application, management, distribution status and existing problems of foreign assets, focus on the construction of foreign assets common benefit mechanism, take the 
following measures:

(1) Defined clearly rights and interests of foreign assets (property rights, management rights, income rights, etc.) of cooperative, inclusion of shares, asset maintenance and other mechanisms, construct asset subsidy system of tobacco companies to cooperative, especially investment direction and investment mode of assets.

(2) Determine the application mechanism of cooperative foreign assets, build a set of fairness and efficiency asset utilization system.

(3) Clear allocation mechanism of cooperative foreign assets income, establish common benefit mechanism of order enterprise subsidies cooperation members.

In the future, we should focus on (enterprises, cooperatives, members )industrial relations, cooperative governance mechanism(governance structure, constitution of property rights, decision system), operating mechanism, distribution system, opportunism prevention, explore foreign assets common benefit mechanism from asset specificity, transaction costs, equity and efficiency.

\section{Acknowledgements}

Research on evaluation of tobacco farmers classification and differential management in southwestern Guizhou (2011-15); Study on the mechanism of foreign assets of tobacco farmers cooperatives inclusive (2015-9); Guizhou Province Science and Technology Fund project ( Qiankehe J [2015] No. 2028); Science and technology project of China National Tobacco Corp Guizhou Branch (201224)

\section{References}

[1] Zheng Weixin. Problems and Countermeasures in the financial management of the farmer specialized cooperative [J]. Management and technology of small and medium sized enterprises (late Journals),2014,11:61-62.

[2] Liu Lei. Research on agricultural assets accounting of farmer specialized cooperative [J]. Friends of accounting,2014,05:109-112.

[3] Zhang Xiaoshan. Some thoughts on promoting the healthy development of farmer cooperatives in China [J].Chinese farmer cooperative,2015,04:44-46.

[4] Jette E. H. The important role of civil society groups in farmer specialized cooperative [J]. Journal of Knowledge-based Innovation in China, 2012,24(2): 404-413.

[5] Horbach J. Determinants of environmental innovation-New evidence from German panel data sources farmer specialized cooperative [J]. Research Policy,2007,18(1): 112-123. 